\title{
Wildlife Protection in the USSR
}

\author{
A. G. Bannikov
}

Professor Bannikov describes how the USSR has created nature reserves to protect individual rare species so that today all endangered mammals are protected in reserves or sanctuaries; several rare species have been greatly increased in numbers and reintroduced in other areas. The article is the talk Professor Bannikov, who is a Vice-President of the FPS, gave at the Society's Annual General Meeting on July 5 in London.

The protection of rare animals is one of the most important functions of our nature reserves. The choice of a reserve area is often determined by the fact that it is already inhabited by rare animal species. This was a fundamental criterion when nature reserves were first created in the USSR, and they were given names which defined their main aim: the Barguzin Sable Reserve, on the eastern shore of Lake Baikal, for example; the Voronezh and the Berezina Beaver Reserves in European Russia and the Khoper Muskrat Reserve on the river Khoper. Later, when the idea developed that the reserves should have a wider function than simply the protection of particular species, that they should operate as 'standard' biomes, they lost the names connected with the original objectives. But even today the existence of rare flora and fauna species in a given area is still an important criterion for its selection as a nature reserve.

In the past nature reserves have prevented the disappearance and guaranteed the restoration of a number of species that were on the verge of extinction. The story of the rescue of the wisent or European bison Bison bonasus is well known. By 1976 there were already 16 centres in the USSR where the bison could breed naturally and without restriction. There are now more than 400 free-ranging European bison, and more than 600 hybrid European/North American bison in the Caucasus.

The beaver Castor fiber had almost vanished from the USSR by 1920 . Only a few dozen families remained in the Voronezh oblast, on the Berezina river in Byelorussia, and on the Konda and Sos'va rivers in the northern Urals. Reserves were created in these places, and the beaver re-established, and over 3000 have been translocated from the Voronezh Reserve alone in the 50 years since its creation. Their descendants in the areas of reintroduction now number more than 70,000 , and the total population in the USSR is now over 400,000 . Since 1962 licensed hunting has been permitted in a number of regions.

On the north-east shore of Lake Baikal the sable Martes zibellina only survived in inaccessible, stony outcrops where there were no more than 20-30 until the Barguzin Nature Reserve was established there. Within twenty years the sable had colonised the entire reserve and were spreading into surrounding areas. In the 1930s this reserve was supplying about 150 sable every year for natural resettlement and had become the main source for re-introductions into areas of Siberia where sable had been exterminated. Similarly, the Lapland Nature Reserve, established on the Kola Peninsula when it contained about 100 wild reindeer Rangifer tarandus, had become the central habitat for more than 20,000 by the 1960 s. 


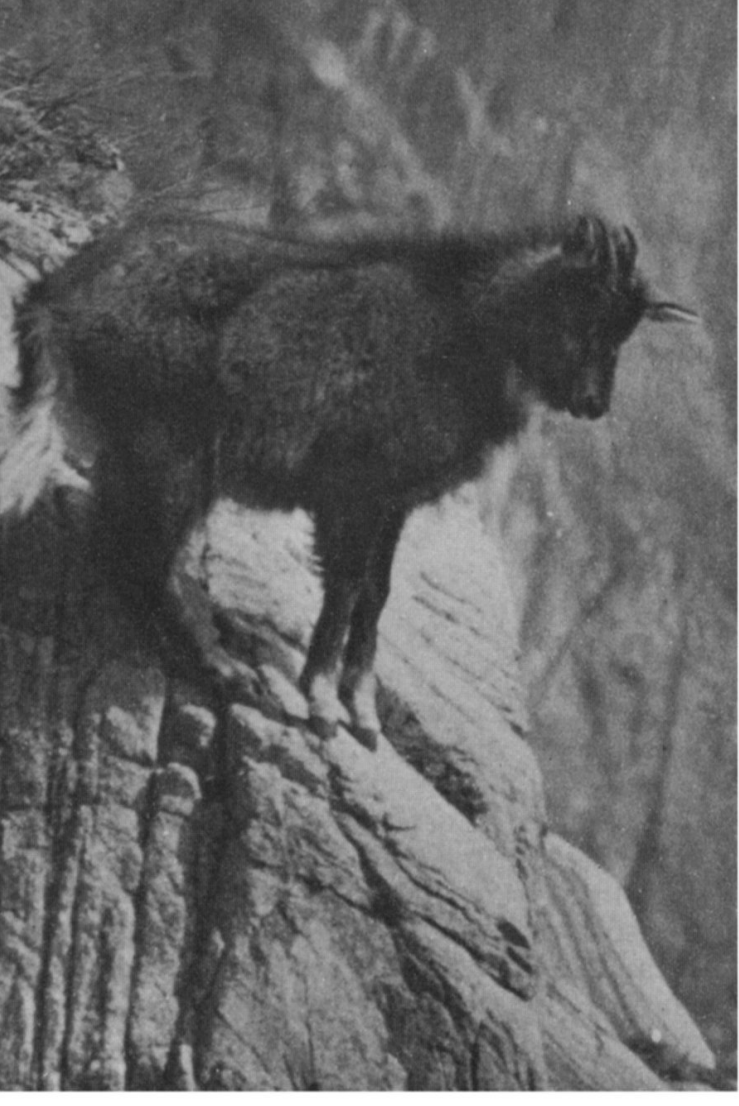

IN USSR RESERVES

GORAL in Sikhote-Alinsky Reserve left V.E. Kostoglad

FEMALE SAIGA A. G. Bannikov

WILD GOATS in Caucasky Reserve M.A.

Kotov
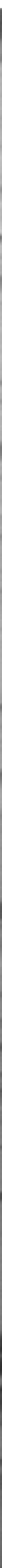
The survival of the rare Bokharan deer Cervus elaphus bactrianus, a race of the red deer, was safeguarded by the Tigrovaya-Balka Nature Reserve, in Tadzhikistan, and the Aral-Paygambar Nature Reserve, in Uzbekistan. There are now more than 400 in these two reserves, and they are being used in a programme of both natural and artificial resettlement.

The kulan Equus hemionus, the wild ass of the Kirghiz steppes, was on the verge of extinction, with not more than 200 head surviving in Badkhyz, in Turkmenia, when a nature reserve was established there. By 1976 numbers had increased to 1254. Similarly the Caucasus Nature Reserve has played a major role in the protection and re-establishment of the chamois Rupicapra rupicapra and the Caucasian mountain goat Capra caucasica, whose numbers there have increased more than 15-fold.

The Amur or Siberian tiger Panthera tigris longipilis, the eastern leopard $P$. pardus orientalis, the spotted deer Cervus nippon, and the goral Naemorhedus goral have only survived thanks to the existence of the Sikhote-Alin and Lazov Nature Reserves in the south of the Far East. The numbers of goral and spotted deer outside the nature reserves are insignificant: over 90 per cent of the gorals (about 300) are concentrated in these two reserves, and more than 95 per cent of the aboriginal spotted deer (about 200) are to be found in the Lazov Nature Reserve.

In recent years the nature reserves have played a major role in restoring the numbers of Persian gazelle Gazella subgutturosa. Formerly this was the commonest ungulate in the deserts of Central Asia and Trans-Caucasia, but numbers steadily declined throughout its natural habitat until by 1960 there were only 130 in Trans-Caucasia and extinction threatened. But with the creation of a nature reserve in the Shirvan steppe, covering 70,745 hectares, and the establishment of two special sanctuaries, the gazelle's numbers began to increase and by 1976 there were almost 3000 in Eastern Trans-Caucasia. Altogether in Central Asia, there are now about 20,000; of these about 1000 are to be found in the reserves, including more than 600 in Badkhyz. This reserve provides a safe refuge for many other rare species, including leopard, caracal lynx Felis caracal, honey badger Mellivora capensis, striped hyena Hyaena hyaena and Turkmenian mountain sheep Ovis ammon cycloceros, of which there are more than 600 , representing over 80 per cent of the entire USSR population of this subspecies.

Rare birds are also protected in the nature reserves. The Astrakhan Nature Reserve in the Volga delta was established mainly to safeguard the colonies of the disappearing white heron Egretta alba, glossy ibis Plegadis falcinellus, spoonbill Platalia leucorodia, pelican, and grey goose Anser anser, and to provide a haven for the mass gatherings of moulting ducks. The Lebyazhi Island Nature Reserve in the Crimea, close to the north-west coast, is an important centre for moulting mute swans Cygnus olor and for wintering whooper swans $C$. cygnus; between 2000 and 5000 of those beautiful birds gather here. On the Caspian the Kyzyl-Agach Nature Reserve, on the south-west shore, and the Krasnovodsk Nature Reserve, on the south-east shore, are of great importance for wintering aquatic birds, including red-breasted goose Branta ruficollis. The Kurgal'dzhino Nature Reserve in Kazakhstan was established to protect nesting flamingos Phoenicopterus ruber, grey geese and mute swans, and it is only thanks to the Kandalashka Nature Reserve on the shores and islands of the Barents and White Seas that 


\section{BOKHARAN MOUNTAIN SHEEP in the Badkhysky Reserve A.G. Bannikov}

the numbers of eider duck Somateria mollisima and of several other birds have been restored.

From the earliest days the nature reserves have had the status of scientific establishments and been permanently staffed by scientists. Long-term, continuous studies of rare and threatened species are pursued there, and it is largely thanks to the work of the permanent scientific staff that the ecology of the sable, beaver, elk Alces alces, spotted deer, kulan, goral, Caucasian mountain goat, and saiga Saiga tatarica, besides that of aquatic and gallinaceous birds, is now understood. These studies provide the scientific basis for the protection, restoration and rational utilisation of these animal resources.

At the beginning of 1977 there were 114 nature reserves in the USSR, covering 9.2 million hectares, and new ones are being created every year. By 1980 it is expected that there will be a further 21 covering an additional 3.3 million hectares.

To what extent do these reserves provide protection for rare species today?

The Red Book of the USSR currently includes 64 species and subspecies of mammals; 63 of birds; 20 of reptiles, and 8 of amphibians. Two categories have been established for mammals and birds: Category A covers species threatened with extinction, and Category $\mathrm{B}$ rare species.

Of the 20 species and subspecies of Category A land mammals (i.e. excluding whales and pinnipeds) 18 are protected in reserves, and two, the 
markhor Capra falconeri and the Bokharan mountain sheep Ovis ammon bochariensis, are protected in sanctuaries. Of the 30 species and subspecies of Category $B$ land mammals, 14 occur in nature reserves and 9 in sanctuaries, and specially protected areas have been provided for the remaining seven, mainly small rodents and bats. Among A and B category birds, almost all species have breeding sites in nature reserves, with the exception of some Arctic sandpipers and stints, Calidris, which inhabit the expanses of arctic tundra as yet barely disturbed by man.

Of reptiles and amphibians the overwhelming majority have also been included in reserves; only 4 species of lizard and snake known to science only through isolated specimens are to be found outside reserve areas, and in the near future it is planned to establish nature reserves in all the places where rare species are found in order to guarantee their survival.

But this is still not enough. Very extensive nature reserves are necessary to maintain big populations of large mammals, especially of wide-ranging, migratory ungulates and large birds of prey. Obviously, it is not possible to establish huge reserves everywhere. The Persian gazelle, for example, requires hundreds of thousands of hectares. Only 6-8 tigers live permanently in the 310,000 hectares Sikhote-Alin Nature Reserve, and in the 116,520 hectares of the Lazov Nature Reserve there are only $4-6$. Obviously the survival of the species cannot be ensured by numbers of this order, and this is even more true of migratory birds, which need not only protected breeding areas, but safe wintering places and migration routes.

Consequently, the nature reserves, for all their great importance, cannot by themselves ensure the survival of all species, and for some it is necessary to combine protected areas with a system for protecting them throughout their natural habitat. This principle is implemented by means of the absolute protection of all species listed in the Red Book.

Some rare species have an obvious need for special 'nurseries' or farms, where they can be bred in captivity or semi-captivity so that they can subsequently be reintroduced into the wild, as was successfully done with the European bison. Such farms not only facilitate the speedier restoration of rare species, but also make possible a closer study of their ecology, as has happened on the elk farm in the Pechorsk Nature Reserve. One such nursery is in Armenia for the Trans-Caucasian mountain sheep where 80 animals are kept, and a farm covering 8000 hectares is now being established on the outskirts of Bokhara for the Persian gazelle.

But with all this, there is no doubt that international co-operation and the mutual exchange of information are of enormous importance in the business of protecting rare species.

For the translation of this paper we are indebted to Mrs Mary Curries of the Great Britain/USSR Association.

\section{Conservation in Papua-New Guinea}

The proceedings of a symposium on Ecology and Conservation in Papua-New Guinea, held at the Wau Ecology Institute in November 1975, are published by the Institute as Pamphlet No 2 (actually a sizeable 150-page paper-backed book) and edited by $K$. P. Lamb and J. L. Gressitt. The papers cover all aspects, and set out some future needs. 